\title{
Oncogene proteins and proliferation antigens in thymomas: increased expression of epidermal growth factor receptor and $\mathrm{Ki} 67$ antigen
}

\author{
N E Gilhus, M Jones, H Turley, K C Gatter, N Nagvekar, J Newsom-Davis, \\ $\mathrm{N}$ Willcox
}

\begin{abstract}
Aims-To examine thymomas for proteins encoded by oncogenes and to determine whether their presence correlates with tumour growth and associated myasthenia gravis.

Methods-Sections of 24 thymomas were incubated with anti-EGF receptor (EGFR), anti-Ki67 antigen, anti-p53, and antibcl-2 antibodies, and then stained using the alkaline phosphatase/anti-alkaline phosphatase (APAAP) technique. Cell suspensions and epithelial cell cultures from some of the tumours were also studied.

Results-Whereas EGF-R expression was not detected in any of the controls (but only in a 20 week old fetus), it was detected in neoplastic epithelial cells of all thymomas, and was most strongly expressed in metastases and in samples from donors with severe myasthenia gravis. Ki67 labelling was also increased, especially in the larger thymomas. Epithelial expression of both of these markers was confirmed in fresh cell suspensions and monolayer cultures from the five available cases. In contrast, p53 and bcl-2 were not detected in the neoplastic cells, but bcl-2 was present in the intermingling thymocytes.

Conclusions-Neoplastic thymoma cells express EGF-R and Ki67, but there is no concomitant increase in the expression of p53 and bcl-2 proteins. Increased EGF-R expression may result in increased proliferation of neoplastic cells and also in myasthenia gravis. Measurement of EGF$R$ concentrations may be of prognostic value. The bcl-2 staining pattern in $T$ lymphocytes illustrates the broad spectrum of maturational stages in thymoma lymphocytes.

(f Clin Pathol 1995;48:447-455)
\end{abstract}

Keywords: Thymoma, myasthenia gravis, oncogenes.

Nuffield Institute of Pathology, University of Oxford, John Radcliffe Hospital, Oxford

M Jones

$\mathrm{H}$ Turley

K C Gatter

Correspondence to: Dr N E Gilhus, Department of Neurology, University of Bergen, N-5020 Bergen,

Norway.

Accepted for publication

26 September 1994 errations in proto-oncogene product such as the epiderma growth factor receptor (EGF-R) will promote cell growth. Ligands binding to this surface membrane receptor activate its intracellular tyrosine kinase and thereby increase the mitotic rate of the cell. ${ }^{2}$ EGF-R expression is also increased in several epithelial tumour cell types. $^{3}$ Another proto-oncogene, bcl-2, encodes two proteins of the inner mitochondrial membrane that extend cell survival by blocking programmed cell death (apoptosis) ${ }^{4}$; bcl- 2 proieins were originally found only in $B$ and $T$ cells but have now been detected in many epithelial cells and their tumours. By contrast, Ki67 is a nuclear antigen that reflects cell proliferation; its expression varies greatly during the cell cycle and is increased in many tumours. ${ }^{5}$

Tumour suppressor genes (antioncogenes) have an inverse function to that of the protooncogenes and suppress or regulate growth. The $\mathrm{p} 53$ protein is the product of a tumour suppressor gene, but its exact function remains unclear. ${ }^{6}$ Mutations in the p53 gene can promote growth. Expression of the p53 protein is often greatly increased when the gene is mutated in tumours, although increased p53 immunostaining cannot be equated with the presence of a mutation. ${ }^{78}$

Thymomas are thymic epithelial cell tumours, but often generate abundant non-neoplastic $T$ lymphocytes at various stages of maturation. The structural and cellular differentiation patterns of the neoplastic epithelial cells are always heterogeneous. Histological markers do not correlate well with their invasiveness or malignancy. ${ }^{910}$ Most thymomas remain encapsulated, but local infiltration and pleural metastases occur in 15 to $25 \%$ of cases. A particular feature of thymomas is their association with the autoimmune disease myasthenia gravis ${ }^{1112} ; 30-60 \%$ of patients with thymomas develop myasthenia gravis at some stage. Autoimmune pure red cell aplasia is also seen in about $5 \%$, but other autoimmune disorders do not occur at an increased frequency. The development of myasthenia gravis in patients with thymomas is believed to be caused by sensitisation of developing $T$ cells against autologous muscle-like antigens, perhaps including the acetylcholine receptor (AcChR), expressed by the neoplastic epithelial cells in these tumours. ${ }^{1314}$ Cofactors are probably necessary to activate these potentially reactive $T$ cells which normally lie dormant.

In the present study we have examined 24 thymomas for various proteins encoded by oncogenes known to influence growth of epithelial cells and tumours. Thymoma sections, 
Table 1 Mouse monoclonal antibodies used for the examination of thymoma markers

\begin{tabular}{llll}
\hline Antibody & Antigen & Immunoglobulin class & Source \\
\hline LP34 & Keratin & IgG & Dako, Glostrup, Denmark \\
MNF116 & Keratin & IgG & Dako \\
MR6 & Corticoepithelium & IgG & Prof MA Ritter, London, UK \\
NA1/34 & CD1 & IgG & Prof AJ McMichael, Oxford, UK \\
3D4 & CD3 & IgG & Dako \\
MAS037 & Fibronectin & IgM & Seralab, Crawley Down, UK \\
EGFR1 & EGF-R & IgG & Dako \\
Ki67 & Ki67 antigen & IgG & Dako 17 \\
DO7 & p53 & IgG & Prof D Lane, Dundee, UK \\
p240 & p53 & IgG & Prof D Lane \\
18.01 & p53 & IgG & Prof D Lane \\
bcl-2 100 & bcl-2 & IgG & Reference 18 \\
\hline
\end{tabular}

fresh cell suspensions, and epithelial cell cultures were stained with antibodies directed against EGF-R, Ki67, p53, and bcl-2. The findings were then correlated with tumour size, lymphocellularity, corticomedullary differentiation, invasiveness, and with the presence of myasthenia.

\section{Methods}

Fresh thymoma tissue samples were obtained from 21 patients, nine men and 12 women, who presented with myasthenia gravis (confirmed on clinical examination and electromyography) and with elevated serum antibodies against muscle $\mathrm{AcChR}$, ranging from 0.55 to $149 \mathrm{nmol} / 1$ (median $18.2 \mathrm{nmol} / 1$ ). Myasthenia gravis was severe prior to thymomectomy (Osserman grade $2 \mathrm{~B}$ or worse) in eight patients, and mild to moderate (Osserman grade $2 \mathrm{~A}$ or better) in 13 patients. Fresh thymomas were also obtained from three patients without myasthenia gravis (two men and one woman) who had no muscle weakness; only one had a marginally positive AcChR antibody titre. The mean age at thymomectomy was 45 years (range 17-64 years).

Control thymus tissue was obtained during cardiac surgery from seven children aged from four days to four years, and from one 20 week old aborted fetus.

\section{THYMOMA PATHOLOGY}

Of the primary tumours, nine were large $\left(>100 \mathrm{~cm}^{3}\right)$ and six were small $\left(<20 \mathrm{~cm}^{3}\right)$. Representative blocks of tissue were fixed in formalin, conventionally stained and examined microscopically. Thymomas from three patients showed extracapsular infiltrative growth on microscopy. In addition, three samples were taken of pleural metastases and one of a local tumour recurrence.

All 24 thymomas were lymphoepithelial in origin-that is, composed of neoplastic epithelial cells with a variable admixture of lymphocytes. Twenty one consisted of polygonal, rounded/oval neoplastic cells with occasional or rare foci of spindle shaped cells, but in three thymomas from patients with myasthenia gravis spindle cells predominated (two of them infiltrating locally). Three small non-infiltrating, polygonal cell thymomas and one spindle cell thymoma were partially lymphocyte depleted by prior corticosteroid treatment. ${ }^{15}$ The patients without myasthenia gravis had not undergone treatment with corticosteroids; their thymomas were all large and contained mainly polygonal cells.

\section{THYMOMA TISSUE SECTIONS}

Representative tissue samples were snap-frozen in isopentane precooled in liquid nitrogen. Cryostat sections $6-8 \mu \mathrm{m}$ in diameter were mounted on to clean glass slides, dried for 18 hours, fixed in acetone for 10 minutes, dried, wrapped in aluminium foil, and stored at $-20^{\circ} \mathrm{C}$.

\section{THYMOMA CELL SUSPENSIONS}

Suspensions were prepared from 19 samples, consisting of about $90 \%$ of the entire tumour, and total yields, mainly of $\mathrm{T}$ cells, were estimated..$^{15}$ Epithelial rich clumps were isolated from two polygonal cell and one spindle cell sample. ${ }^{16}$

For indirect immunofluorescence, cell suspensions were incubated with first layer monoclonal antibodies, washed, and then with class specific second layer anti-immunoglobulin antibodies (see later), before washing and analysis by fluorescence microscopy or on a fluorescence activated cell sorter (FACScan, Becton Dickinson, USA). Cell suspensions were sometimes cytocentrifuged and stained with a second antibody and conjugate after fixation.

\section{THYMOMA CULTURES}

Neoplastic epithelial cells were cultured from four fresh thymomas and from one of nine cryopreserved suspensions. ${ }^{14}$ Cells were cultured for eight to 10 weeks and were $85-95 \%$ pure. Samples grown on coverslips were fixed in $95 \%$ methanol before being stained for intracellular antigens by indirect immunofluorescence. Both the frequency of positive cells and the staining intensity were recorded. In some experiments cells were cultured in interferon- $\gamma 500 \mathrm{U} / \mathrm{ml}$ (British Biotechnology, Oxford, UK) for 72 hours before staining.

\section{ANTIBODIES}

The mouse monoclonal antibodies used in this study are listed in table 1 . A polyclonal rabbit antikeratin antibody (Dako, Glostrup, Denmark) was used in the double staining experiments.

The second layer antibodies were goat antimouse IgG fluorescein conjugated, goat antimouse IgM rhodamine or phycoerythrin conjugated, or goat antirabbit IgG rhodamine conjugated (all from Southern Biotechnology Assoc., Birmingham, Alabama, USA). A rabbit antimouse IgG antibody (Dako) was used to stain tissue sections.

\section{IMMUNOHISTOLOGY}

Tissue sections were stained using the alkaline phosphatase/antialkaline phosphatase (APAAP) technique. ${ }^{19}$ Briefly, tissue sections were incubated in undiluted hybridoma supernatant at room temperature for 30 minutes 

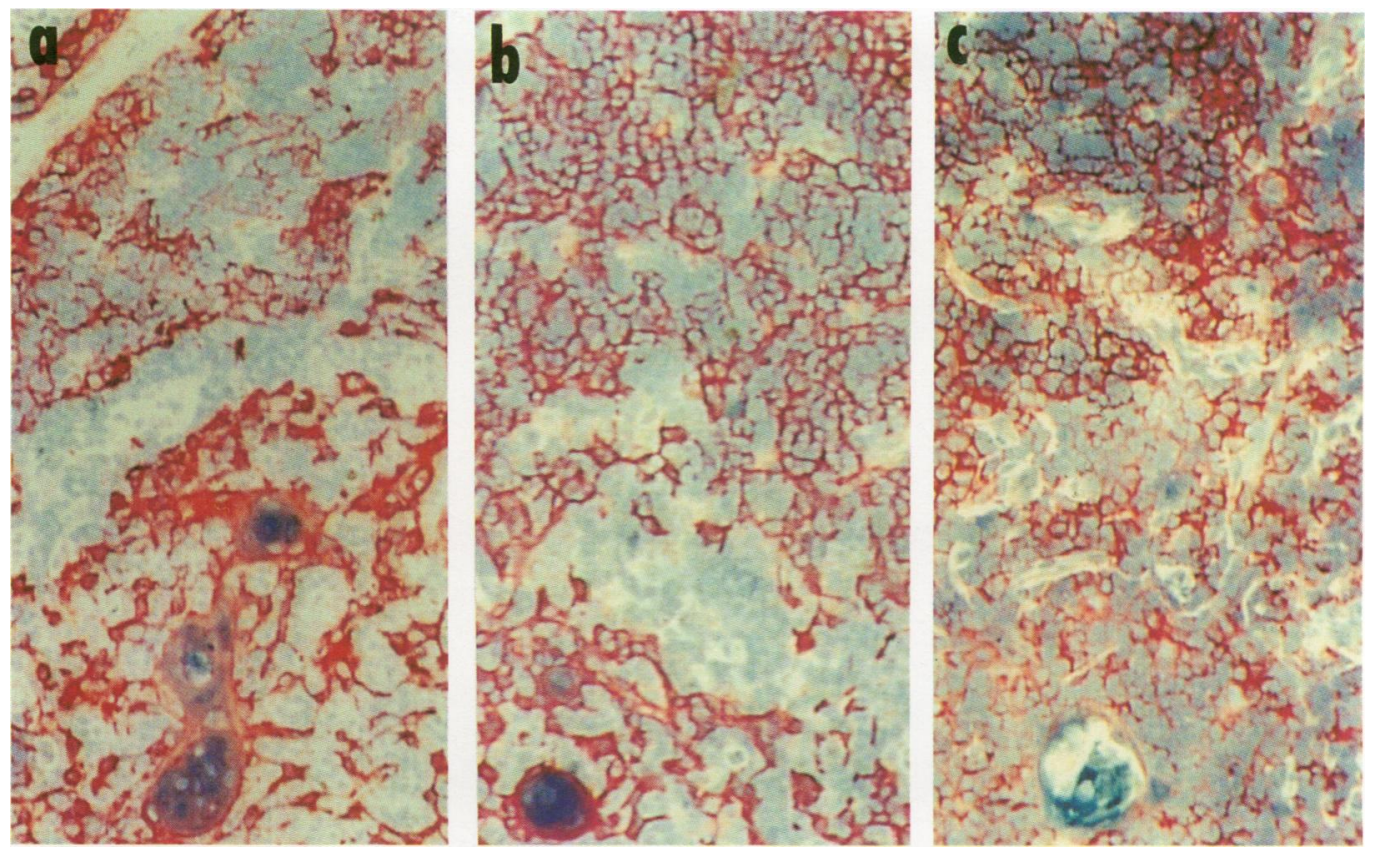

Figure 1 Tissue sections from normal thymus with cortex and medulla stained for keratins: $a$, antibody LP34; $b$, antibody MNF116; c, antibody MR6 (× 40).

(p240 and 18.01 antibodies diluted 1 in 5). Then the rabbit antimouse IgG antibody was applied for 30 minutes, and preformed APAAP immune complexes for another 30 minutes. The antimouse antibody and then the APAAP complexes were added again for another 10 minutes. Sections were washed in Tris buffered saline between each incubation. The colour was finally developed with naphthol AS-B1 phosphate (Sigma, Poole, Dorset, UK) and New Fuchsin (Sigma), and the sections briefly counterstained with haematoxylin before being mounted. The frequency of positive cells and the staining intensity were recorded. To identify the positive cells conclusively, indirect immunofluorescence was used for selected double labelling experiments. For both methods, controls were included with irrelevant first layer antibodies or none at all.

\section{Results}

CORTICAL AND MEDULLARY EPITHELIAL

STAINING PATTERNS

In the normal thymus the LP34 antikeratin antibody stained most epithelial cells in the medulla and in the subcapsular cortex but only a minority of those seen in the deeper cortex (fig 1a). By contrast, the MNF116 and MR6 antibodies stained most cortical but few
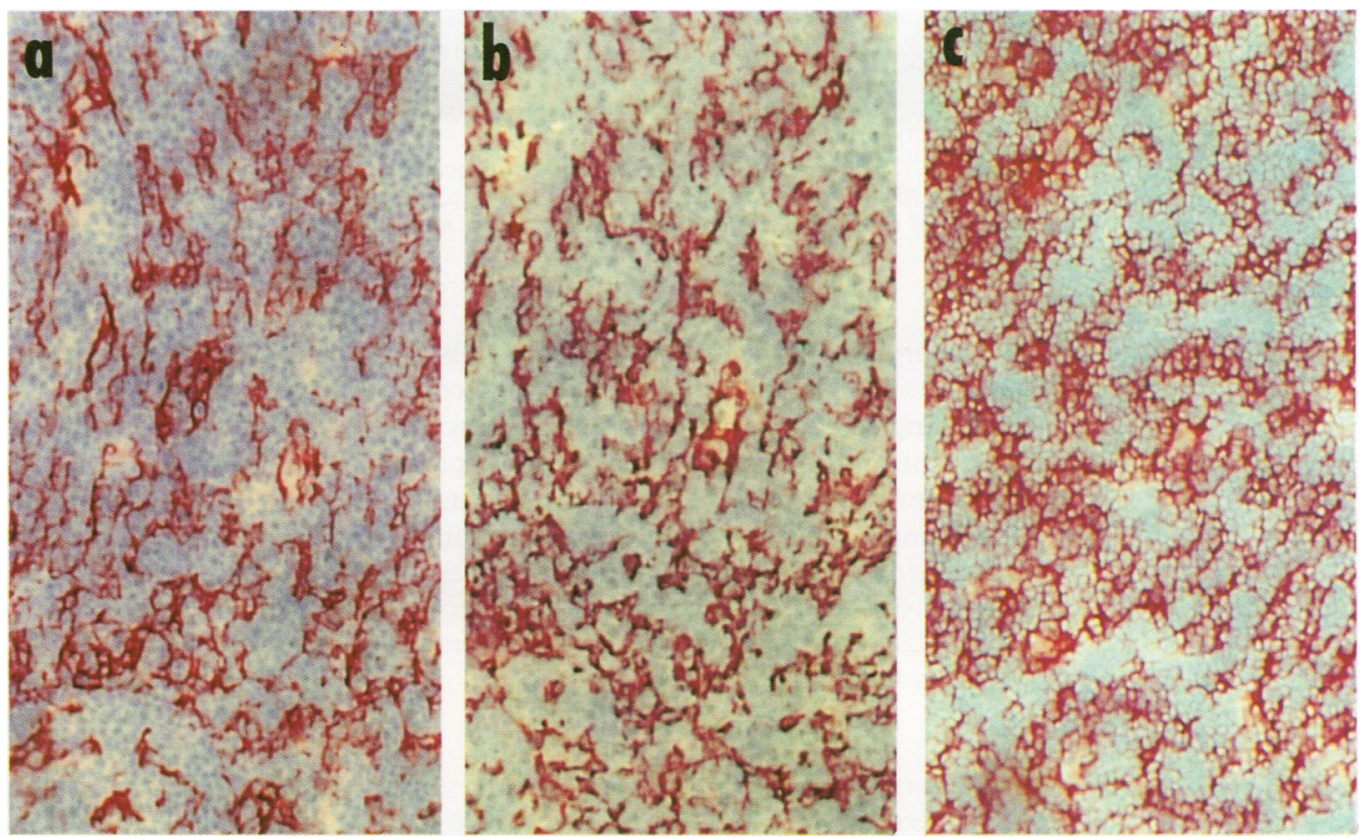

Figure 2 Tissue sections from a polygonal non-infiltrative thymoma stained for keratins: $a$, antibody LP34; b, antibody MNF116; c, antibody MR6 (× 40). 

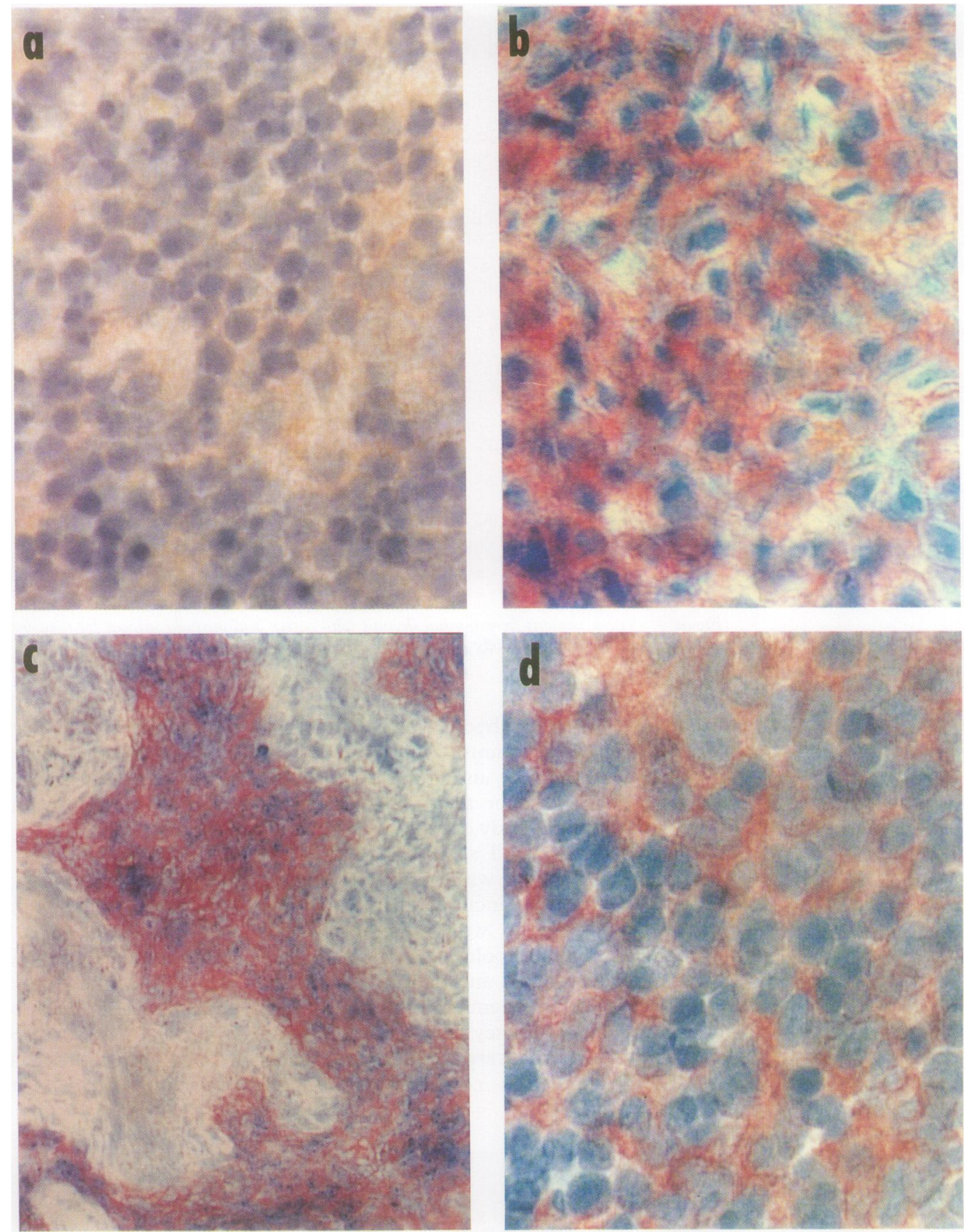

Figure 3 Tissue sections stained for EGF-R: a, normal thymus unstained (cortex and medulla) $(\times 240) ; b$, fetal thymus (20 weeks) positively stained $(\times 240)$; c, polygonal recurrent thymoma with intense staining $(++++)$ but no staining of connective tissue $(\times 40)$; d, polygonal, non-infiltrative thymoma with intense staining $(\times 240)$.

medullary or subcapsular epithelial cells (figs $1 \mathrm{~b}$ and $1 \mathrm{c})$. The thymomas could be grouped according to the staining pattern produced by these antibodies. In two thymomas the pattern was mainly medullary and in six it was predominantly cortical, whereas the remaining 16 tumours were corticomedullary with either strong (pattern A) or weak (pattern B) MNF116 staining. LP34 and MR6 staining patterns were strong in both (fig 2).

\section{EGF RECEPTOR}

In tissue sections there was no detectable staining for EGF-R in any of the control samples, even in the subcapsular epithelial cells (fig 3a).
However, epithelial cells in the fetal thymus (gestational age 20 weeks) showed staining of variable intensity, with an apparently cytoplasmic distribution (fig $3 b$ ).

In sharp contrast, in all 24 thymomas most epithelial cells stained for EGF-R, but other cell types did not (figs $3 c$ and $3 d$ ). Connective tissue areas were always negative, whether infiltrated by $T$ lymphocytes or not. Diffuse EGF-R staining was observed throughout the cytoplasm; in one metastatic thymoma, however, staining was apparently confined to the cell surface and had a network pattern. While most epithelial cells were stained in all samples, there were often weak or negative foci; thus, the staining intensity varied in different areas 


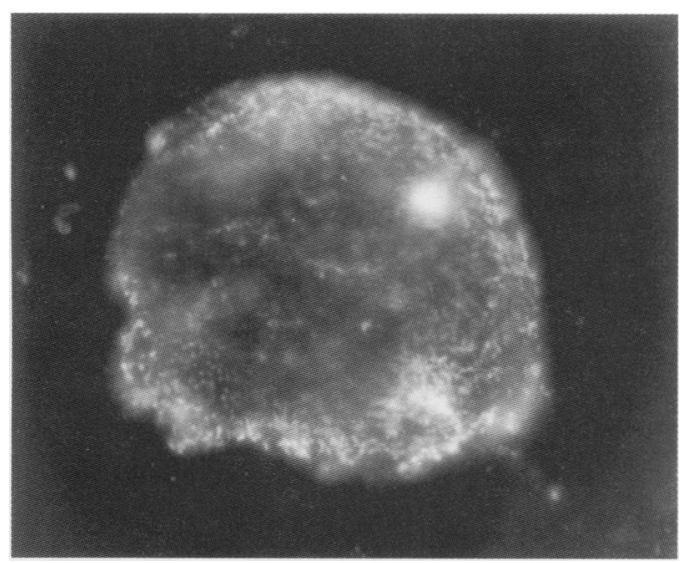

Figure 4 Surface membrane EGF-R staining of a cell in a thymoma polygonal cell epithelial culture $(\times 480)$.

and the frequency of positive cells ranged from 30 to $95 \%$. Both these indices tended to be greatest in the patients with severe myasthenia gravis (table 2). In the three patients without myasthenia gravis, labelling was generally weak $(+-++)$. Staining for EGF-R was widespread and intense $(++++)$ in two of the four metastatic/recurrent thymomas (fig 3c); it was almost as intense in the third $(+++)$, but was weak in the fourth $(+)$. It was also weak in the spindle cell and medullary thymomas $(+-++)$. Otherwise, there was no obvious correlation between EGF-R labelling and thymoma size, cortical differentiation (table 2), lymphocyte content, or epithelial cell growth in culture, or with the patients' age, sex or serum antiAcChR antibody titre.

In cell suspensions from the three fresh thymomas examined EGF-R was expressed on a very small minority of the cells, and ranged from approximately 5 to $40 \%$ of the keratin positive cells identified by double immunofluorescence staining. This weak, speckled or granular EGF-R membrane staining seen on the day of thymectomy correlated well with that in tissue sections from the same thymomas. However, within 24 to 48 hours in culture it often disappeared, although $10-30 \%$ of the epithelial cells remained positive in two of five long term cultures (fig 4). This staining did not correlate with the in vitro growth rate and was not restored by culture with interferon- $\gamma$.

\section{KI67}

In the control sections Ki67 stained many nuclei in the cortex (20-40\%), but only a small minority in the medulla (1-5\%) (fig 5a). Nearly all of the positive cells were thymocytes. Their overall frequency was similar in the fetal thymus, but the distinction between cortical and medullary areas was less obvious.

In thymoma sections nuclear labelling for Ki67 showed either an even staining pattern that was strongest along the nuclear membrane (APAAP) (figs 5b and 5c), or a more granular pattern (immunofluorescence) (figs $6 \mathrm{a}$ and $6 \mathrm{~b}$ ). Ki67 staining was highly variable both within and between tumours. In most there were areas with either high $(10-70 \%)$ or low $(0-5 \%)$ proportions of stained cells (figs $5 \mathrm{~b}$ and $5 \mathrm{c}$ ). Several showed even stronger staining than in the normal cortex (see later). Both the thymomas with a medullary keratin/MR6 staining pattern showed a medullary Ki67 picture too, but otherwise there was no correlation between epithelial (LP34, MNF116, MR6) and Ki67 staining patterns. The transition between areas within a thymoma could be sharp, as between cortex and medulla in normal thymus, but was sometimes more gradual.

Most cells with nuclear Ki67 staining were $\mathrm{T}$ lymphocytes, but in most cases some larger epithelial cells were positive too. This was especially obvious in the spindle cell thymomas (marked difference between epithelial and lymphoid cells) and in lymphocyte depleted tumours or tumour areas. Epithelial Ki67 labelling was confirmed by double staining for $\mathrm{Ki} 67$ and keratin both in sections from three thymomas (fig 6a) and in cytocentrifuged spreads from the three fresh thymoma suspensions examined, where the proportion of Ki67 positive cells correlated very well with that seen in the tissue sections. Again, the great majority of the cells stained were thymocytes. However, in the five epithelial cell cultures $1,10,13,15$, and $20 \%$, respectively, of the cells expressed distinct and granular Ki67 antigen in the nucleus (fig $6 \mathrm{~b})$. Double labelling confirmed that the positive cells were epithelial cells (keratin positive) and not fibroblasts (fibronectin positive). The proportion of Ki67 positive cells was highest in the more rapidly proliferating cultures and remained remarkably constant up to 10 weeks, but was reduced in late cultures with slower growth.

Nuclear Ki67 labelling of epithelial cells in sections was hard to quantify where lymphocytes abounded. However, it was almost negative in the epithelial cells of two of the three spindle cell samples, whereas the third showed a more typical mixture of cortical and medullary patterns. Nuclear Ki67 labelling apparently correlated negatively with EGF-R staining

Table 2 All 24 thymoma patients graded for EGF-R staining, severity of myasthenia gravis, thymoma size, epithelial cell staining pattern, thymoma invasiveness, and for Ki67 nuclear antigen staining. The number of patients is given for each category

\begin{tabular}{|c|c|c|c|c|c|c|c|c|c|c|c|c|c|c|c|c|c|}
\hline \multirow[b]{2}{*}{$E G F-R$} & \multicolumn{3}{|c|}{ Myasthenia gravis } & \multicolumn{3}{|c|}{ Thymoma size } & \multicolumn{4}{|c|}{ Epithelial pattern ${ }^{a}$} & \multicolumn{3}{|c|}{ Invasiveness } & \multicolumn{4}{|c|}{$K i 67^{b}$} \\
\hline & Severe & Moderate/mild & None & Small & Medium & Large & $C$ & $M B$ & $M A$ & $M$ & Met & $\operatorname{Inv}$ & Non-Inv & + & ++ & +++ & ++++ \\
\hline $\begin{array}{l}\text { Intense } \\
\text { Fairly strong } \\
\text { Fairly weak } \\
\text { Weak }\end{array}$ & $\begin{array}{l}4 \\
2 \\
2 \\
0\end{array}$ & $\begin{array}{l}1 \\
3 \\
6 \\
3\end{array}$ & $\begin{array}{l}0 \\
0 \\
1 \\
2\end{array}$ & $\begin{array}{l}1 \\
1 \\
3 \\
1\end{array}$ & $\begin{array}{l}1 \\
2 \\
1 \\
1\end{array}$ & $\begin{array}{l}3 \\
2 \\
5 \\
3\end{array}$ & $\begin{array}{l}1 \\
2 \\
2 \\
1\end{array}$ & $\begin{array}{l}2 \\
3 \\
4 \\
1\end{array}$ & $\begin{array}{l}2 \\
0 \\
2 \\
2\end{array}$ & $\begin{array}{l}0 \\
0 \\
1 \\
1\end{array}$ & $\begin{array}{l}2 \\
1 \\
0 \\
1\end{array}$ & $\begin{array}{l}0 \\
1 \\
1 \\
1\end{array}$ & $\begin{array}{l}3 \\
3 \\
8 \\
3\end{array}$ & $\begin{array}{l}3 \\
3 \\
1 \\
0\end{array}$ & $\begin{array}{l}0 \\
2 \\
2 \\
1\end{array}$ & $\begin{array}{l}1 \\
0 \\
2 \\
1\end{array}$ & $\begin{array}{l}1 \\
0 \\
4 \\
3\end{array}$ \\
\hline
\end{tabular}

${ }^{a}$ C, cortical (LP34 low, MNF116 high, MR6 high); MB, mixed B (LP34 high, MNF116 high, MR6 high); MA, mixed A (LP34 high, MNF116 low, MR6 high);

M, medullary (LP34 high, MNF116 low, MR6 low).
${ }^{b}$ Cortical $(++++)(>20 \%$ of cells); mixed, mainly cortical $(+++)(10-20 \%$ of cells); mixed, medullary/cortical $(++)(5-10 \%$ of cells); medullary $(+)(<5 \%$ ${ }^{b}$ Cortical $(+$ of cells). 

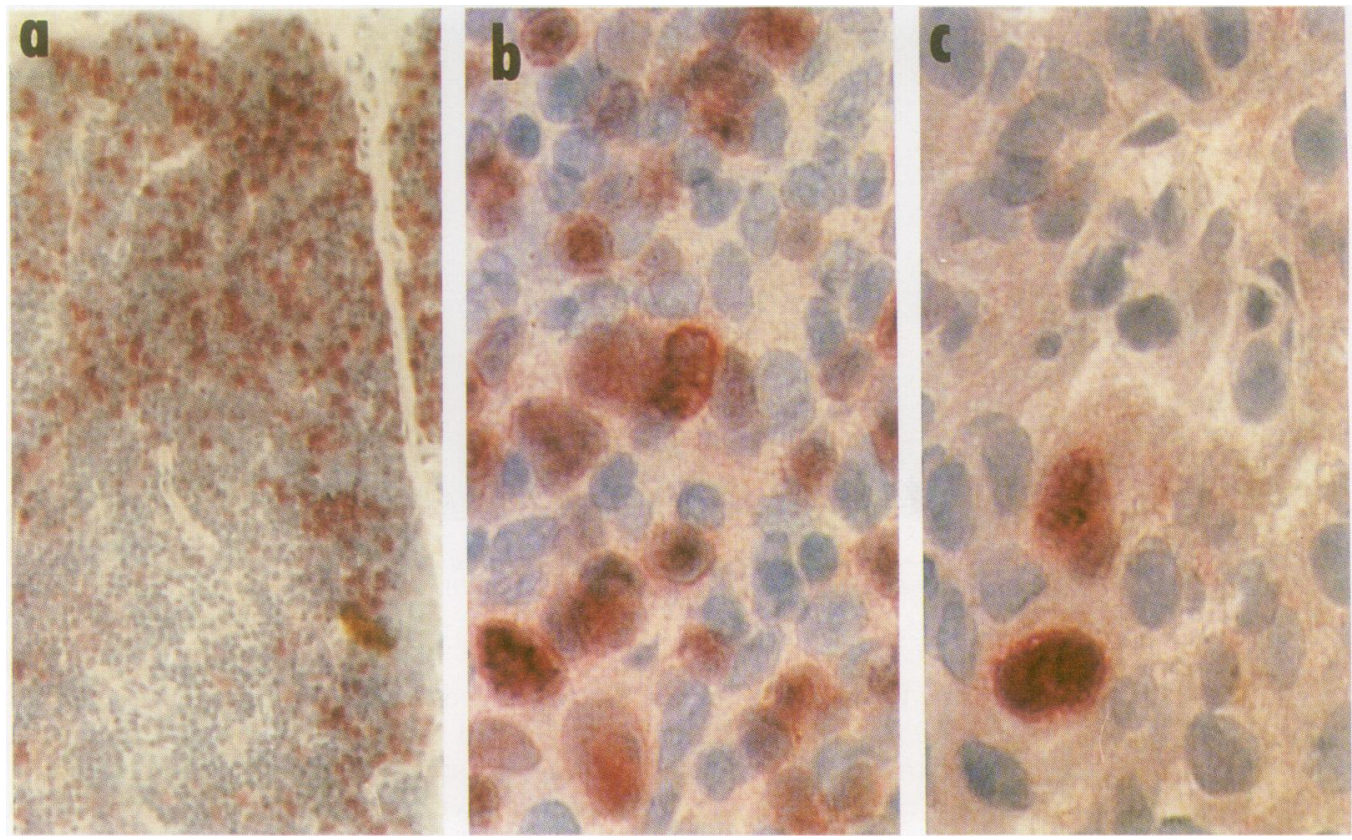

Figure 5 Tissue sections stained for Ki67: $a$, normal thymus with cortex and medulla $(\times 40) ; b$ and $c$, polygonal, noninfiltrative thymoma with many (b) and few (c) cells staining. Very weak cytoplasmic staining also occurred $(\times 240)$.

(table 2), but positively with tumour size; in four of the six small thymomas staining was weak $(+-++)$, but was intense $(++++)$ in four of the nine large tumours and weak in only one of them. Ki67 staining was not especially increased in the invasive or metastatic tumours, or in those with the best growth in culture, and did not correlate with clinical parameters of myasthenia gravis. The proportion of Ki67 positive cells tended to be higher in the thymomas with a high total yield of cell suspension (fig 7).

Cytoplasmic staining by $\mathrm{Ki} 67$ was noted in the outer cortex in two of the eight control samples and in 17 of the thymomas. It was generally weak and diffuse. This cytoplasmic
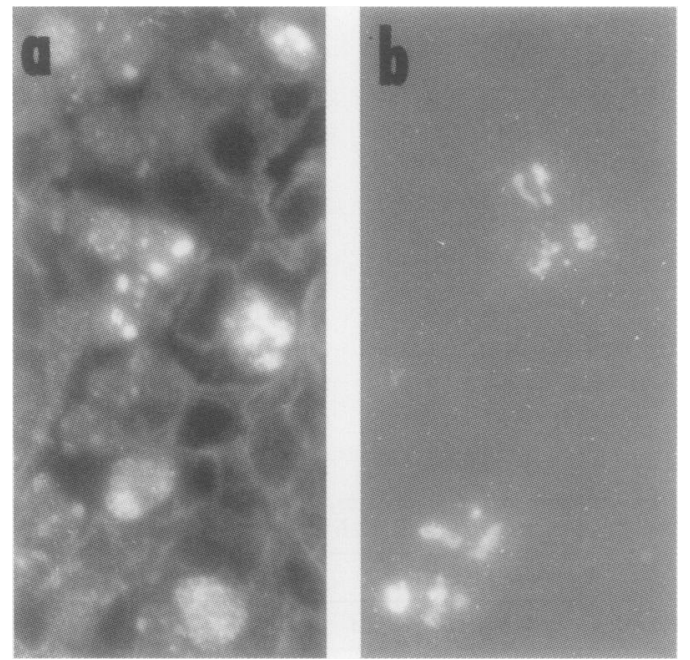

Figure 6 Thymomas stained for Ki67 using indirect immunofluorescence: a, tissue section from a mainly polygonal, non-infiltrative thymoma stained with mouse anti-Ki67 and rabbit antikeratin and with fluorescein isothiocyanate and tetrarhodamine isothiocyanate conjugated second layer antibodies, respectively; $b$, granular nuclear Ki67 staining in a thymoma epithelial spindle cell culture $(\times 240)$. labelling did not correlate with tumour size or invasiveness, with clinical parameters, or with duration of tissue storage.

\section{P53 PROTEIN}

None of the cells in the sections from the 24 thymomas or in the five cultures stained for the $\mathrm{p} 53$ protein with any of the three different antibodies used. The normal thymus sections were equally negative.

\section{BCL-2 PROTEIN}

In control thymic specimens the anti-bcl-2 antibody stained $60-80 \%$ of thymocytes in the medulla, but only about $10 \%$ in the cortex (fig $8 a)$. In the fetal sample a similar fraction of the total thymocytes was stained. There was no obvious staining of epithelial cells or of other stromal elements in either.

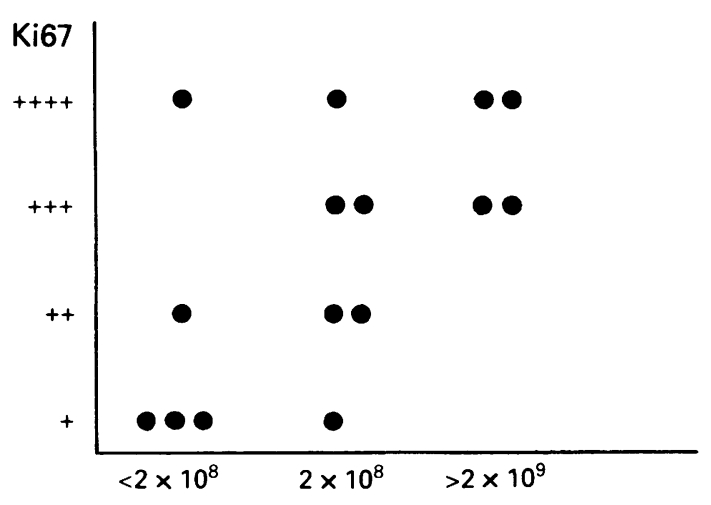

\section{Cell yield}

Figure 7 Ki67 staining in tissue sections with respect to the cell yield from the fresh thymoma (total number of cells obtained per $\left.\mathrm{cm}^{3}\right)$. Staining was graded from weak $(+-++)$ to intense $(++++)$. Yields were estimated for 15 thymomas. 

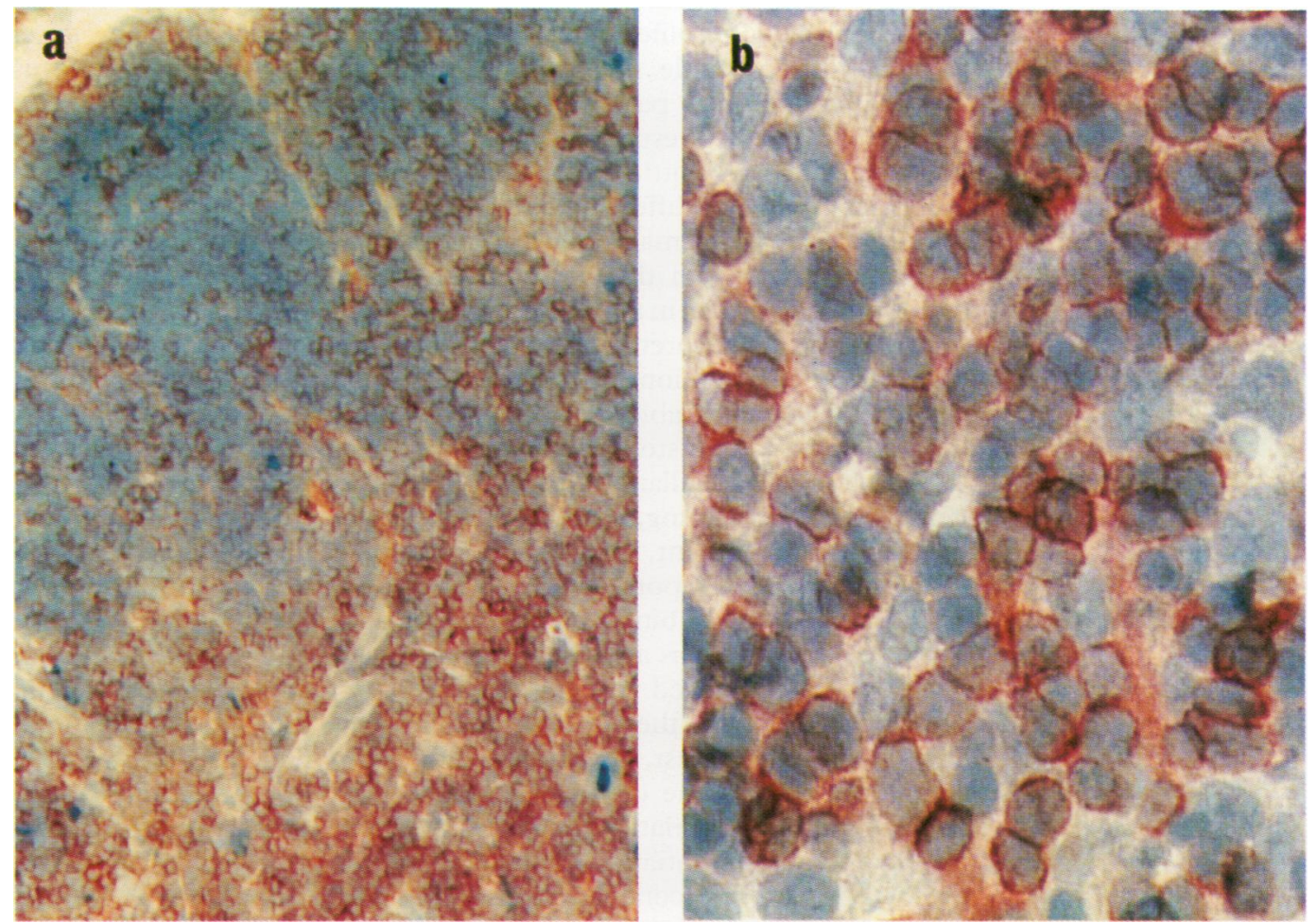

Figure 8 Tissue sections stained for bcl-2: a, normal thymus with cortex and medulla $(\times 40) ; b$, polygonal noninfiltrative thymoma $(\times 240)$.

In the thymoma samples a variable proportion of cells was stained (fig 8b); these cells were apparently almost exclusively thymocytes, and no definite epithelial labelling was seen, even in lymphocyte depleted areas. Staining was entirely cytoplasmic and perinuclear. The proportion of cells stained varied between approximately $2 \%$ and $60 \%$. It was greater in areas with abundant CD1 positive and especially $\mathrm{CD} 3$ positive $\mathrm{T}$ cells. As with $\mathrm{Ki} 67$ positive lymphoid cells, the proportion stained was also higher in the thymomas with a high total yield of cells in suspension $\left(>2 \times 10^{9}\right.$ cells per $\mathrm{cm}^{3}$ tumour). However, this did not correlate with other aspects of epithelial cell growth or with the presence of myasthenia gravis. None of the five cultures of thymoma epithelial cells stained for bcl-2.

\section{Discussion}

This paper shows for the first time that neoplastic epithelial cells in thymomas express the oncogene protein EGF-R and the proliferation marker Ki67, with no increase in p53 or bcl-2 protein expression, even in metastases. Thymus from infants was chosen as the normal control because thymomas resemble it much more closely than the adult thymus both in lymphocellularity and bulk. These samples, however, showed no epithelial labelling for EGF-R, which was only seen during fetal life when cell proliferation is at its highest. The expression of the Ki67 antigen in a small minority of normal epithelial cells cannot be completely ruled out because of the excess of positive thymocytes. That probably explains why Ki67 labelling in a previous study was noted only in the lymphoid cells of thymomas. ${ }^{20}$ Double staining of thymoma cells in situ and in culture conclusively establishes that some neoplastic epithelial cells were positive for Ki67.

In addition to their neoplastic growth thymomas are particularly interesting because of their association with myasthenia gravis. This might reflect sensitisation of developing $T$ cells by epitopes of $\mathrm{AcChR}^{14}$ or other muscle antigens $^{13}$ expressed by the neoplastic epithelial cells. Interestingly, in this study, EGF-R expression tended to be lower where myasthenia was absent or mild, and higher in severe myasthenia gravis. This is not an effect caused by intensive therapy for severe myasthenia gravis as very few of these patients had taken immunosuppressive drugs before thymectomy. It is more probable that in patients with myasthenia gravis neoplastic epithelial cells express not only more EGF-R, but also more of the muscle related antigens, or in a more immunogenic form, and so stimulate a stronger or more diverse response. There was no similar correlation between the severity of myasthenia gravis and thymoma size, invasiveness or other aspects of thymoma growth potential.

Myasthenia gravis accompanied by a thymoma tends to be more severe and has a higher associated mortality. ${ }^{2122}$ A prognostic assessment of individual thymomas is difficult to give in clinical practice but might have important therapeutic implications. We attempted to correlate the expression of EGF-R and Ki67 with tumour invasiveness, lymphocellularity and size. The metastatic thymomas tended to have high EGF-R expression but a variable Ki67 antigen content. The larger thymomas 
tended to have more nuclear Ki67, indicating intense epithelial proliferation. Even with a relatively small sample size and variation in histology and growth pattern within a single thymoma, ${ }^{910}$ these results should be representative as there is little variation in immune parameters between different thymoma tissue blocks. ${ }^{15}$ Proliferation markers apart from Ki67 did not correlate with thymoma invasiveness or metastatic potential in a recent study. ${ }^{23}$ However, we should interpret the results from that small series with caution; prognostication has not proved to be reliable in previous studies using a variety of histological classifications based on corticomedullary differentiation, epithelial or keratin staining, nuclear morphology, or lymphocyte content, although some correlations have been reported. ${ }^{24-29}$

When the EGF-R binds its ligand, its intrinsic tyrosine kinase is activated and cell proliferation is enhanced. ${ }^{2}$ Its expression is increased in many epithelial tumours, such as those of the lung, breast, and urinary and genital tracts. ${ }^{30-32}$ In some of these, there seems to be a modest correlation between EGF-R expression, dedifferentiation and poor prognosis. ${ }^{33}$ High EGF-R concentrations have also been detected on human glioma cells. ${ }^{34}$ Overexpression of EGF-R by thymoma cells is one further sign of its wide contribution to increased cell proliferation in neoplasia. The growth in culture of human tumour cells expressing high amounts of EGF-R is inhibited by anti-EGF$R$ antibodies ${ }^{35}$ and EGF was always used in our thymoma epithelial cell cultures. ${ }^{16} \mathrm{Al}-$ though the effect of EGF-R on cell proliferation is, for a large part, mediated by the ras protein, ${ }^{36}$ ras activation was not found in the only thymoma examined. ${ }^{37}$ Overexpression of EGF-R on thymoma cells could be caused by gene amplification, overexpression of specific gene transcription factors, or post-translational influences. ${ }^{3438}$

Ki67 shows cell cycle associated expression and there is generally a good correlation between Ki67 immunoreactivity and other indices of cell proliferation, ${ }^{539}$ as was also seen in our thymoma cultures. Strong Ki67 labelling in the larger tumours confirms its status as a marker of proliferation, as has been confirmed for several tumour types. ${ }^{5041}$ Weak staining for Ki67 in two of the three spindle cell thymomas may reflect their less aggressive growth. ${ }^{27}$ However, as in several previous studies, ${ }^{5041}$ we saw no strong correlation with anaplasia. Perhaps surprisingly, epithelial Ki67 staining correlated negatively with EGF-R labelling. Even if these markers are expressed at different phases of the cell cycle, one might still expect them to vary in parallel in an asynchronous cell population. Conceivably, lack of EGF may increase the concentration of its receptor but reduce cell proliferation.

Although the Ki67 antigen is usually detected in the nucleus, the cytoplasmic localisation observed in many thymoma cells in this study has been noted previously. ${ }^{43}$ This antibody probably detects a cross-reacting cytoplasmic epitope. In theory, some true $\mathrm{Ki67}$ antigen might not yet have reached the nucleus or could have artefactually leaked from it during fixation or storage. The absence of Ki67 labelling in fresh thymoma cell suspensions or cultures may support this, but perhaps not the patchiness of the staining. Whatever the explanation, the cytoplasmic versus nuclear staining pattern did not correlate with neoplastic and myasthenia gravis features or with tissue handling parameters, but is yet another sign of the variation within and among thymomas.

The p53 protein was not detected in any of the thymomas. As it is usually expressed at undetectable low concentrations in normal tissues, we cannot exclude a decrease in p53 expression in thymomas, perhaps resulting from deletions within the p53 gene. However, increased expression is the more usual result of p53 gene mutations and has been seen in many of the common cancers. ${ }^{74}$ These mutations convert p53 from a restraining to an enhancing or dysregulatory factor in the control of cell growth. Similarly, it has been suggested that the bcl-2 protein can extend cell survival not only in lymphomas but also in other neoplasias including epithelial tumours. ${ }^{45}{ }^{46}$ However, our study excludes any major role for bcl2 in thymoma neoplastic epithelial cells.

The heterogeneous bcl-2 expression observed confirms the broad spectrum of maturational stages in thymoma lymphocytes, as in normal thymocytes. The normal function of the bcl-2 protein is to extend survival in tissues where the life span is limited by apoptosis, ${ }^{4}$ and it plays a particularly important role in the thymus. When immature thymocytes develop surface $\mathrm{T}$ cell receptors, they are very vulnerable to apoptosis, but can be saved by positive selection by the cortical epithelium. This almost certainly acts through bcl- 2 and related pathways. ${ }^{47}$ The increased Ki67 positive thymocyte frequency in thymomas, observed in this study and in others, ${ }^{20}$ and their very disorganised architecture imply great scope for aberrations in positive as well as in negative selection. Overexpression of bcl- 2 could be a sign of defects in the latter, and could thus lead to the propagation of autoaggressive $T$ cells in thymomas. Moreover, as most $\mathrm{Ki} 67$ positive thymocytes are usually also CD45 RO positive and are destined for intrathymic death, ${ }^{48}$ their abundance in thymomas may be further evidence of selection defects. However, as the spectrum of autoimmune diseases associated with thymomas is so highly restricted, we believe that active sensitisation of specific $\mathrm{T}$ cells within these tumours is more likely than abnormally permissive positive selection or generally defective negative selection.

In conclusion, thymoma epithelial cells can overexpress EGF-R which partially correlates with the severity of myasthenia gravis and with tumour invasiveness. This could result from mutations such as those found in many human neoplasms. Together with the increased Ki67 positive frequency in these cells, this may be a sign of the uncontrolled growth that is the hallmark of neoplasia.

Supported by the Unger-Vetlesen Medical Fund, Agnes Sars Legat, The Norwegian Research Council, The Wellcome Trust, 
The Sir Jules Thorn Charitable Trust, and The Imperial Cancer Research Fund.

1 Bishop JM. Molecular themes in oncogenesis. Cell 1991;64: $235-48$.

2 Gill GN. Regulation of EGF receptor expression and function. Mol Reprod Dev 1990;27:46-53.

3 Garcia de Palazzo IE, Adams GP, Sundareshan P, Wong AJ, Testa JR, Bigner DD, et al. Expression of mutated epidermal growth factor receptor by non-small cell lung carcinomas. Cancer Res 1993;53:3217-20.

4 Hockenbery DM, Zutter M, Hickey W, Nehm M, Korsmeyer SJ. BCL2 protein is topographically restricted in tissues characterized by apoptotic cell death. Proc Natl Acad Sci USA 1991;88:6961-5.

5 Yu CC-W, Woods AL, Levison DA. The assessment of cellular proliferation by immunohistochemistry: a review of currently available methods and their applications. of currently available methods

6 Vile RG. p53: a gene for all tumours? $B M f$ 1993;307: $1226-7$.

7 Iggo R, Gatter K, Bartek J, Lane D, Harris AL. Increased expression of mutant forms of p53 oncogene in primary lung cancer. Lancet 1990;i:675-9.

8 Gaidano G, Ballerini P, Gong JZ, Inghirami G, Neri A, Newcomb EW, et al. p53 mutations in human lymphoid malignancies: association with Burkitt lymphoma and chronic lymphocytic leukemia. Proc Natl Acad Sci USA 1991;88:5413-17.

9 Rosai J, Levine GD. Tumours of the thymus. In: Atlas of tumour pathology. Washington DC: Armed Forces, Intumour pathology. Washington
stitute of Pathology, 1976:1-228.

10 Otto HF. Tumours of the thymus and their nomenclature. Virchows Arch A Pathol Anat 1991;419:257-60.

11 Gilhus NE, Matre R, Aarli JA. The immunology of thymoma in myasthenia gravis and other neurological diseases. In: Aarli JA, Behan WMH, Behan PO, eds. Clinical neuroimmunology. Oxford: Blackwell Scientific Publications, 1987:259-74.

12 Willcox N. Myasthenia gravis. Curr Opin Immunol 1993;5: 910-17.

13 Gilhus NE, Aarli JA, Christensson B, Matre R. Rabbit antiserum to a citric acid extract of human skeletal muscle staining thymas from myasthenia gravis patients. $f$ Neuroimmunol 1984;7:55-64.

14 Marx A, O'Connor R, Geuder KI, Hoppe F, Schalke B, Tzartos $\mathrm{S}$, et al. Characterization of a protein with an Tzartos S, et al. Characterization of a protein with an acetylcholine receptor epitope from myasthenia

15 Willcox N, Schluep M, Ritter MA, Schuurman HJ, Newsom-Davis J, Christensson B. Myasthenic and non-myasthenic thymoma: an expansion of a minor cortical epithelial cell subset? $A m \mathcal{F}$ Pathol 1987;127:447-60.

16 Gilhus NE, Willcox N, Harcourt G, Nagvekar N, Beeson $\mathrm{D}$, Vincent $\mathrm{A}$, et al. Antigen presentation by thymoma epithelial cells from myasthenia gravis patients to potentially pathogenic $T$ cells. 7 Neumimmunol 1994;56: 65-76.

17 Gerdes J, Schwab U, Lemke H, Stein H. Production of mouse monoclonal antibody reactive with a human nuclear antigen associated with cell proliferation. Int $f$ Cancer 1983;31:13-20.

18 Pezzella F, Tse AGD, Cordell JL, Pulford KAF, Gatter KC, Mason DY. Expression of the bcl-2 oncogene protein is not specific for the $14 ; 18$ chromosomal translocation. $\mathrm{Am}$ f Pathol 1990;137:225-32.

19 Cordell JL, Falini B, Erber WN, Ghosh AK, Abdulaziz $\mathrm{Z}$, MacDonald S, et al. Immunoenzymatic labeling of monoclonal antibodies using immune complexes of alkaline phosphatase and monoclonal anti-alkaline phos-

phatase (APAAPcomplexes). F Histochem 1984;32:219-29.

Chilosi M, Iannucci A, Menestrina $F$, Lestani M, Scarpa A, Bonetti F, et al. Immunohistochemical evidence of active thymocyte proliferation in thymoma: its possible role in the pathogenesis of autoimmune diseases. $A m \mathcal{F}$ role in the pathogenesis
Pathol 1987;128:464-70.

21 Oosterhuis HJGH. The natural course of myasthenia gravis: a long term follow up study. $\mathcal{F}$ Neurol Neurosurg Psychiatry a long term follow

22 Mygland Å, Aarli JA, Matre R, Gilhus NE. Ryanodine receptor antibodies related to severity of thymoma-associated myasthenia gravis. $f$ Neurol Neurosurg Psychiatry 1994;57:843-6.

23 Tateyama H, Mizuno T, Tada T, Eimoto T, Hashimoto T, Masaoka A. Thymic epithelial tumours: evaluation of malignant grade by quantification of proliferating cell nuclear antigen and nucleolar organizer regions. Virchows A Pathol Anat Histopathol 1993;422:265-9.
24 Monden Y, Tanioka T, Maeda M, Masaoka A, Nakahara $\mathrm{K}$, Kawashima Y, et al. Malignancy and differentiation of neoplastic epithelial cells of thymoma. $\mathcal{F}$ Surg Oncol 1986; neoplastic

25 Hirokawa K, Utsuyama M, Moriizumi E, Hashimoto T, Masaoka A, Goldstein AE. Immunohistochemical studies in human thymomas: localization of thymosin and various cell markers. Virchows Arch B Cell Pathol 1988;55:371-80.

26 Nomori H, Horinouchi H, Kaseda S, Ishihara T, Torikata C. Evaluation of the malignant grade of thymoma by morphometric analysis. Cancer 1988;61:982-8.

27 Kirchner T, Schalke B, Marx A, Müller-Hermelink HK. Evaluation of prognostic factors in thymic epithelial tumours. Thymus 1989;14:195-203.

28 Kirchner T, Schalke B, Buchwald J, Ritter M, Marx A, Müller-Hermelink HK. Well-differentiated thymic carcinoma: an organotypical low-grade carcinoma with relationship to cortical thymoma. Am f Surg Pathol 1992; 16:1153-69.

29 Fukai I, Masaoka A, Hashimoto T, Yamakawa Y, Mizuno $\mathrm{T}$, Tanamura $\mathrm{O}$. Cytokeratins in normal thymus and thymic epithelial tumors. Cancer 1993;71:99-105.

30 Maruo T, Yamasaki M, Ladines-Llave CA, Mochizuki M. Immunohistochemical demonstration of elevated expression of epidermal growth factor receptor in the neoplastic changes of cervical squamous epithelium. Cancer 1992;69:1182-7.

31 Charpin C, Devictor B, Bonnier P, Andrac L, Lavaut MN, Allasia C, et al. Epidermal growth factor receptor in breast cancer: correlation of quantitative immunocytochemical assays to prognostic factors. Breast Cancer Res Treat 1993; 25:203-10.

32 Rao JY, Hemstreet GP III, Hurst RE, Bonner RB, Jones $\mathrm{PL}$, Min KW, et al. Alterations in phenotypic biochemical markers in bladder epithelium during tumorigenesis. Proc markers in bladder epithelium during tum

33 Koenders PG, Beex LV, Kienhuis CB, Kloppenborg PW, Benraad TJ. Epidermal growth factor receptor and prognosis in human breast cancer: a prospective study. Breast Cancer Res Treat 1993;25:21-7.

34 Collins VP, James CD. Gene and chromosomal alterations associated with the development of human gliomas. FASEB F 1993;7:926-30.

35 Modjtahedi H, Eccles S, Box G, Styles J, Dean C. Immunotherapy of human tumour xenografts overexpressing the EGF receptor with rat antibodies that block growth factor-receptor interaction. Br f Cancer 1993;67:254-61.

$36 \mathrm{Li} \mathrm{N}$, Batzer A, Daly R, Yajnik V, Skolnik E, Chardin P, et al. Guanine-nucleotide-releasing factor hSos 1 binds to $\mathrm{Grb} 2$ and links receptor tyrosine kinases to Ras signalling. Grb2 and links receptor

37 Rodenhuis S, Slebos RJ. Clinical significance of ras oncogene activation in human lung cancer. Cancer Res 1992; 52(Suppl 9):2665-9

38 Kitadai Y, Yasui W, Yokosaki H, Kuniyasu H, Haruma K, Kajiyama $\mathrm{G}$, et al. The level of transcription factor $\mathrm{Spl}$ is correlated with the expression of EGF receptor in human gastric carcinomas. Biochem Biophys Res Commun 1992; 189:1342-8.

39 Janossy G, Campana D, Akbar A. Kinetics of T lymphocyte development. In: Iversen $\mathrm{OH}$, ed. Current topics in pathology. Vol 79. Cell kinetics of the inflammatory reaction. Berlin, Heidelberg: Springer-Verlag, 1989:59-96.

40 Lloyd SN, Brown IL, Leake RE. Ki-67 antibody immunostaining in benign and malignant human prostatic disease. Int $\mathcal{F}$ Biol Markers 1992;7:256-9.

41 Magno WB, Hirschfield L Bhuiya T, Harrison G, Mir R. Correlation of proliferative index (PCNA reactivity and $\mathrm{Ki}-67$ reactivity) in primary breast carcinoma with hormone status, lymph node status, and disease-free survival. Conn Med 1992;56:667-9.

42 Apte SS. Ki-67 monoclonal antibody (Mab) reacts with a proliferation associated nuclear antigen in the rabbit Oryctolagus cuniculus. Histochemistry 1990;94:201-4.

43 Brown DC, Gatter KC. Monoclonal antibody Ki-67: its use in histopathology. Histopathology 1990;17:489-503.

44 Marshall CJ. Tumor suppressor genes. Cell 1991;64:313-26.

5 Brada M. BCL2 gene: current relevance to clinical oncology. Eur 7 Cancer 1992;28:270-2.

46 Pezzella F, Turley H, Kuzu I, Tungekar MF, Dunnill MS, Pierce CB, et al. bcl-2 protein in non-small-cell lung Pierce CB, et al. bcl-2 protein in non-

47 Akbar AN, Salmon M, Savill J, Janossy G. A possible role for bcl-2 in regulating T-cell memory: a "balancing act" between cell death and survival. Immunol Today 1993;14: 526-32.

48 Gillitzer R, Pilarski LM. In situ localization of CD45 isoforms in the human thymus indicates a medullary location for the thymic generative lineage. $f$ Immunol 1990;144: 66-74. 